\title{
Challenges associated with peripheral arterial disease in women
}

This article was published in the following Dove Press journal:

Vascular Health and Risk Management

10 March 2014

Number of times this article has been viewed

\section{Jessica Barochiner \\ Lucas S Aparicio \\ Gabriel D Waisman}

Hypertension Section, Internal Medicine Department, Hospital Italiano de Buenos Aires, Buenos Aires, Argentina

Video abstract

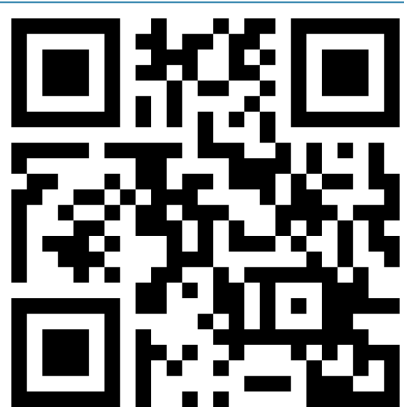

Point your SmartPhone at the code above. If you have a QR code reader the video abstract will appear. Or use: http://dvpr.es/NfMHt
Correspondence: Jessica Barochiner Hypertension Section, Internal Medicine Department, Hospital Italiano de Buenos Aires, 4190 Juan D Perón Highway, Buenos Aires $\mathrm{CI}$ I8I ACH, Argentina Tel +54 II 49590200 Fax +54 I| 49584454 Email jessica.barochiner@hospitalitaliano. org.ar

\begin{abstract}
Peripheral arterial disease (PAD) is an increasingly recognized disorder that is associated with functional impairment, quality-of-life deterioration, increased risk of cardiovascular ischemic events, and increased risk of total and cardiovascular mortality. Although earlier studies suggested that PAD was more common in men, recent reports based on more sensitive tests have shown that the prevalence of PAD in women is at least the same as in men, if not higher. PAD tends to present itself asymptomatically or with atypical symptoms more frequently in women than in men, and is associated with comorbidities or situations particularly or exclusively found in the female sex, such as osteoporosis, hypothyroidism, the use of oral contraceptives, and a history of complications during pregnancy. Fat-distribution patterns and differential vascular characteristics in women may influence the interpretation of diagnostic methods, whereas sex-related vulnerability to drugs typically used in subjects with PAD, differences in risk-factor distribution among sexes, and distinct responses to revascularization procedures in men and women must be taken into account for proper disease management. All these issues pose important challenges associated with PAD in women. Of note, this group has classically been underrepresented in research studies. As a consequence, several sex-related challenges regarding diagnosis and management issues should be acknowledged, and research gaps should be addressed in order to successfully deal with this major health issue.
\end{abstract}

Keywords: peripheral arterial disease, women, diagnosis, management

\section{Introduction}

Peripheral arterial disease (PAD) is an increasingly recognized disorder that is associated with functional impairment, quality-of-life deterioration, increased risk of cardiovascular ischemic events, and increased risk of total and cardiovascular mortality. ${ }^{1-3}$ The major risk factors for PAD are diabetes mellitus, cigarette smoking, advanced age, dyslipidemia, and hypertension., ${ }^{2,4}$ Patients with PAD are less likely to receive proper treatment for these atherosclerotic risk factors than those who have been diagnosed with coronary artery disease (CAD). ${ }^{2,5}$

Although earlier studies suggested that PAD was more common in men, recent reports based on more sensitive tests have shown that the prevalence of PAD in women is at least the same as in men, if not higher. Given that PAD is related to age, that the worldwide population is aging, and that women account for the majority of the elderly, it is expected that PAD among women will be of increasing concern in the near future. ${ }^{6}$ However, several challenges regarding diagnosis and management should be acknowledged, and research gaps should be addressed in order to successfully deal with this major health issue. 
While the term "PAD" refers to a wide range of noncoronary syndromes, the scope of this review focuses on the lower-limb arteries, below the bifurcation of the abdominal aorta.

\section{Epidemiology of PAD in women Prevalence}

Traditionally, PAD has been reported to be more prevalent in men than in women. ${ }^{6,7}$ However, studies that support this affirmation were based on the presence of symptoms to diagnose PAD. ${ }^{6}$ In more recent studies, it has been noticed that PAD is asymptomatic or presents with atypical symptoms in up to $90 \%$ of subjects, ${ }^{2}$ and that the use of a more sensitive noninvasive test, such as the ankle-brachial index (ABI), allows for an approximately fivefold increase in the detection of cases detected by a history of intermittent claudication. ${ }^{6} \mathrm{In}$ contrast with the earlier understanding, the aforementioned studies report a prevalence of PAD among women between $3 \%$ and $29 \%,{ }^{6}$ at least the same as in men, or even higher in some of them. A recent review of population-based studies showed that the mean prevalence of PAD was $15.6 \%$ in women and $13.4 \%$ in men. ${ }^{8}$

Given that the overall prevalence of PAD increases with age, that the worldwide population is aging, and that it is estimated that women will account for the majority of those 65 years or older in coming years, an even higher prevalence of PAD among women is expected in the next few decades, which will probably surpass male predominance. ${ }^{6}$ Therefore, the need for proper diagnosis and management of PAD in women is pressing.

\section{Comorbidities}

In primary care, the practicing physician should be aware of concomitant conditions that may either increase or preclude the suspicion of PAD, particularly in women (Table 1). For instance, coexistence of PAD with coronary and carotid artery disease has been typically described. ${ }^{9}{ }^{10}$ However, this association is less frequent in women than in men., ${ }^{9,11}$ As a consequence, women are less likely to be screened and/or treated for PAD on the basis of the presence of coronary or cerebrovascular disease.

Smolderen et a ${ }^{12}$ reported that women recently diagnosed with PAD had fourfold-greater odds for baseline depression than men. This condition may not only influence treatment outcomes but may also preclude seeking medical help, delaying or avoiding proper diagnosis, and should alert the treating physician to screen for PAD.

Heidrich and Hermann ${ }^{13}$ have shown that subjects with PAD have a prevalence of $38.5 \%$ of orthopedic diseases,
Table I Concomitant conditions that may pose a challenge associated with peripheral arterial disease (PAD) detection or management, particularly in women

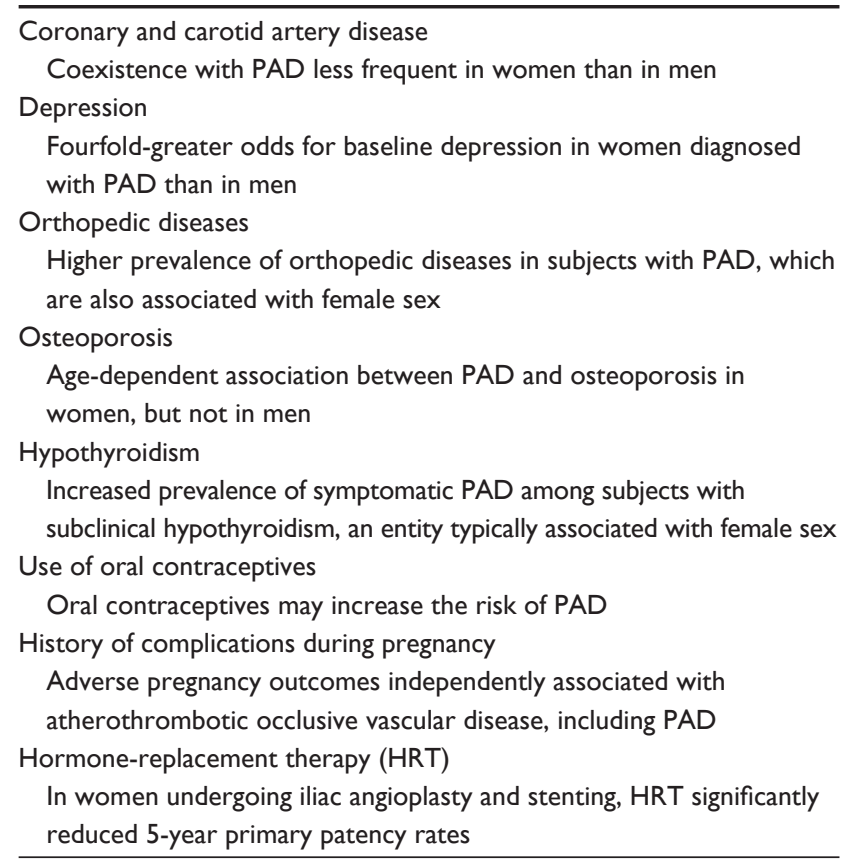

such as arthritis and arthrosis. Given that these comorbidities tend to be associated with female sex,,$^{14,15}$ it is imperative to have a high level of suspicion for proper differential or concomitant diagnosis.

Osteoporosis is another condition that is more prevalent among women. Older women with low bone mineral density (BMD) have a higher prevalence of atherosclerotic vascular disease (coronary artery disease, ischemic stroke or PAD) than older women with normal BMD. ${ }^{16}$ In the Rancho Bernardo study, von Mühlen et al found an agedependent association between PAD and osteoporosis in women, but not in men, ${ }^{17}$ whereas Mangiafico et al found a significantly higher prevalence of PAD in osteoporotic women compared with matched postmenopausal women with normal BMD $(18.2 \%$ versus $3.8 \%, P<0.001) .{ }^{18}$ In a retrospective study in 1,000 postmenopausal women, atherosclerotic vascular disease occurred in $60 \%$ with osteoporosis, $35 \%$ with osteopenia, and $22 \%$ with no osteoporosis or osteopenia $\left(P<0.001\right.$ for all comparisons) ${ }^{19}$ These results suggest that osteoporotic postmenopausal women have an increased cardiovascular risk and a vascular evaluation should be performed in order to identify patients who would benefit from preventive and therapeutic cardiovascular interventions.

On the other hand, hypothyroidism, an entity also associated with female sex, ${ }^{20}$ has been related to PAD. Powell et al 
showed significantly higher thyrotropin levels in women with PAD diagnosed through the ABI compared with women without PAD (control group), ${ }^{21}$ whereas Mya and Aronow found an increased prevalence of symptomatic PAD among subjects with subclinical hypothyroidism compared with euthyroid persons: $78 \%$ versus $17 \%, P<0.001 .{ }^{22}$ Although these results have not been confirmed by other studies, ${ }^{23}$ this is an interesting line of investigation, which might highlight the importance of PAD screening in women with hypothyroidism, an extremely frequent disease in primary practice.

The use of oral contraceptives is associated with an increased risk of venous and arterial thrombosis, and may increase blood pressure (BP) levels. ${ }^{24}$ It has also been noticed that oral contraceptives may increase the risk of PAD. In the RATIO (Risk of Arterial Thrombosis in Relation to Oral Contraceptives) study, an adjusted odds ratio for PAD of 3.8 ( $95 \%$ confidence interval [CI] 2.4-5.8) was found in women aged 18-49 years, using all kinds of oral contraceptives versus no use. ${ }^{25}$ Women may also be at risk for the development of PAD when they have a history of complications during pregnancy. Ben-Ami et al aimed to determine whether adverse pregnancy outcomes were associated with atherothrombotic occlusive vascular disease (AOVD), including PAD. ${ }^{26}$ They conducted a retrospective matched case-control study comparing women aged less than 50 years treated for AOVD with healthy women matched for age and body mass index. On the multivariable analysis, composite pregnancy complications, including intrauterine growth restriction, pregnancy-induced hypertension, and preeclampsia, were independently associated with AOVD. Weissgerber et al measured the ABI in 144 nulliparous women and 1,272 and 271 women with a history of normotensive or hypertensive pregnancies, respectively. ${ }^{27} \mathrm{~A}$ greater odds ratio of PAD (defined by an ABI $\leq 0.9$ ) was found for women with a history of hypertensive pregnancy compared with women with a history of normotensive pregnancy: 1.61 (95\% CI 1.04-2.49). The association remained unchanged after adjustment for cardiovascular risk factors, such as diabetes, smoking status, hypertension, and dyslipidemia. PAD risk was not different between women with a history of normotensive pregnancy and nulliparous women.

With regard to hormone-replacement therapy (HRT), the observational Rotterdam study indicated that long-term HRT may be beneficial. ${ }^{28}$ In this study of 2,196 women aged 55-80 years, a 52\% decreased risk of PAD was observed among women who reported using HRT for over 1 year. In turn, the PARTNERS (PAD Awareness, Risk, and Treatment: New Resources for Survival) program showed a higher HRT use in the group with no PAD compared with other groups manifesting atherosclerosis. ${ }^{11}$ However, larger randomized controlled trials, such as the HERS (Heart and Estrogen/ Progestin Replacement Study) and Women's Health Initiative (WHI) trials, ${ }^{29,30}$ failed to demonstrate a beneficial effect of HRT on PAD. The WHI trials, either with estrogen plus progestin or estrogen alone, noted an increase in peripheral vascular events or reintervention, whereas Timaran et al found that in women undergoing iliac angioplasty and stenting, HRT significantly reduced 5-year primary patency rates. ${ }^{31}$ Therefore, HRT is currently considered a risk factor in women with vascular disease, and it has been suggested that women with PAD should discontinue HRT 4-6 weeks prior to endovascular or surgical revascularization. ${ }^{29,32}$

\section{Mortality}

PAD carries a similar relative risk of death from cardiovascular causes as a history of coronary or cerebrovascular disease. ${ }^{33}$ Remarkably, such risk is similar in both asymptomatic and symptomatic patients. ${ }^{38}$ In women, Vogt et al found that among those with PAD, the adjusted relative risk for all-cause mortality was 3.1 at 4 years, compared with women without PAD. ${ }^{34}$ Few studies have evaluated sexspecific mortality related to PAD. In the ABI Collaboration study of 16 population-based cohort studies, Fowkes et al demonstrated that associations between $\mathrm{ABI}$ values and total and cardiovascular mortality and major coronary events were similar in women and men. ${ }^{36}$ Among women, morbidity and mortality risks were specifically increased with lower $\mathrm{ABI}$ values and with values $\geq 1.4$. In the SHEP (Systolic Hypertension in the Elderly Program) substudy involving 1,537 subjects with PAD, of whom 868 were women, age-adjusted relative risk for mortality was 2.8 at 4 years, compared with 3.0 in men. ${ }^{37}$ Therefore, mortality associated with PAD seems to be similar for women and men, with a two- to threefold-elevated relative risk

\section{Challenges associated with diagnostic aspects of PAD in women Awareness, clinical presentation, and physical examination}

Awareness of PAD in women and men is low compared with knowledge of other cardiovascular diseases: a US survey conducted by Hirsch et al among 2,501 adults older than 50 years showed that three of four adult Americans had no awareness of PAD. ${ }^{38}$ Moreover, populations at highest risk for PAD, such as the elderly and minorities, were the least informed. A Canadian survey provided similar results - two of three adult Canadians were unaware of $\mathrm{PAD}^{39}$ - whereas 
Bush et al reported that PAD knowledge was poor among women at risk for cardiovascular diseases. ${ }^{40}$

Given that women are more likely to obtain primary care than men, ${ }^{41}$ these visits constitute a unique opportunity for PAD screening. For that purpose, educational information provided to primary care physicians could help to improve the early detection and treatment of PAD.

Apart from the fact that both PAD awareness in the general population and the level of suspicion among primary care physicians are low, the clinical presentation of PAD in women tends to be especially misleading. According to the American College of Cardiology Foundation/American Heart Association 2005 practice guidelines for the management of patients with PAD, only $10 \%$ of PAD patients will present with classical symptoms of intermittent claudication, whereas $50 \%$ will have atypical symptoms and the remaining $40 \%$ will be asymptomatic. ${ }^{2}$ Several studies have indicated that asymptomatic disease is even more common among women compared with men. In a study of 1,601 healthy women, the Rose Questionnaire, developed at the London School of Hygiene and Tropical Medicine for detecting PAD, only had 18\% sensitivity in comparison to the $\mathrm{ABI},{ }^{42}$ whereas women with PAD were significantly more likely to be asymptomatic than men (12.6\% versus $9.4 \%$, respectively; $P=0.03$ ) in a Swedish population-based study. ${ }^{43}$ Similar results were reported in a longitudinal study of 2,327 subjects followed for 7.2 years, where the incidence of asymptomatic PAD was $12.4 \%$ in women and $7.8 \%$ in men. ${ }^{44}$ Moreover, the patient's activity level should be properly identified, given that a linear correlation between the severity of the disease and the presence of exertional leg symptoms in women with PAD has been reported only among women who walked more than four blocks. This correlation was not observed in less active women. ${ }^{45}$ Women tend to be not only more asymptomatic but it has also been noticed that symptoms could be masked or misinterpreted as arthritis, osteoporosis, or spinal stenosis, which are also prominent in this population. As a matter of fact, the 187 women included in the WALCS (Walking and Leg Circulation Study) trial of 460 PAD patients were more than twice as likely as men to report the presence of atypical exertional leg symptoms. ${ }^{46}$

Physical examination for PAD detection could be misleading in women. Pulse palpation could be very informative for screening purposes, and auscultation of bruits over the femoral artery, although poorly sensitive, is also suggestive. However, fat is distributed differently among men and women: the latter tend to have a peripheral fat distribution, which is defined as fat deposited in the limbs and hips, particularly in the lower body. ${ }^{47}$ These sex-related characteristics may lead to an erroneous conclusion when examining a woman for PAD-screening purposes.

All the previously described features may contribute to explain why women, when finally diagnosed, have more advanced disease, a higher percentage of critical limb ischemia, and poorer quality of life than men. ${ }^{48,49}$

\section{Diagnostic methods}

Although history and physical examination are of utmost importance for overall cardiovascular risk evaluation and PAD assessment, the use of an objective diagnostic method is critical for proper PAD diagnosis. Several methods are currently available, both invasive and noninvasive. Contrast angiography remains the gold standard for PAD diagnosis. ${ }^{2,54}$ However, it is an invasive method associated with risks, such as local injury to the artery, contrast-induced nephropathy, and radiation exposure. Therefore, inexpensive and risk-free noninvasive methods, such as the ABI and duplex ultrasound, are usually used for PAD screening, whereas more complex, expensive, and invasive methods, such as magnetic resonance angiography (MRA), computed tomography (CT), and contrast angiography, are obtained once PAD has been diagnosed in order to determine more precisely the level and extent of the disease for revascularization purposes (Table 2).

\section{Ankle-brachial index}

Current PAD guidelines establish the ABI as the preferred method for PAD diagnosis., 2,50,51 This noninvasive method has been validated against contrast angiography, showing

Table 2 Diagnostic methods in peripheral arterial disease: sexrelated challenges

\begin{tabular}{|c|c|}
\hline Method & Challenge \\
\hline$\overline{A B I}$ & $\begin{array}{l}\text { Concerns raised regarding the need for different } \\
\text { cutoff values in women } \\
\text { Conditions related to stiff arteries (older age, } \\
\text { diabetes) more frequent in women with PAD }\end{array}$ \\
\hline $\begin{array}{l}\text { Duplex } \\
\text { ultrasound }\end{array}$ & $\begin{array}{l}\text { Difficulty in assessing the lumen in the presence } \\
\text { of highly calcified arteries, a phenomenon more } \\
\text { frequently observed in women } \\
\text { Not useful for areas of open ulcers or excessive } \\
\text { scarring, typical of advanced disease, more } \\
\text { frequently encountered in women } \\
\text { Accuracy diminished in proximal aortoiliac arterial } \\
\text { segments in the context of obesity with peripheral } \\
\text { fat distribution, more common in women }\end{array}$ \\
\hline $\begin{array}{l}\mathrm{CT}, \mathrm{MRA} \text {, and } \\
\text { contrast } \\
\text { angiography }\end{array}$ & $\begin{array}{l}\text { Claustrophobia precluding MRA tolerance more } \\
\text { common in women } \\
\text { lodinated contrast allergy more frequent in } \\
\text { women }\end{array}$ \\
\hline
\end{tabular}

Abbreviations: $A B I$, ankle-brachial index; $C T$, computed tomography; MRA, magnetic resonance angiography; PAD, peripheral arterial disease. 
a sensitivity of $95 \%$ and a specificity of $100 \%$ for an $\mathrm{ABI}$ threshold of $0.9,52$ and it is inversely related to atherosclerotic risk factors and the presence of cardiovascular and cerebrovascular diseases. In the SHEP trial, a low ABI was predictive of total and cardiovascular mortality, ${ }^{53}$ whereas McKenna et al found 5-year mortality of approximately $30 \%$ and $50 \%$ in individuals with an $\mathrm{ABI}$ of 0.7 and 0.4 , respectively. ${ }^{54}$ Remarkably, the study conducted by the Ankle Brachial Index Collaboration group showed that the inclusion of the ABI in the calculation of the Framingham risk score increases the risk category, this effect being more dramatic for women. ${ }^{36}$ This is not a minor finding, given that the Framingham risk score tends to underestimate the risk in women belonging to a low-risk category. Therefore, the use of the ABI may improve the Framingham risk score's ability to classify women's risk more accurately.

Although the ABI is indicated in all subjects at risk of PAD regardless of sex, some studies have suggested that there might be sex-related differences regarding $\mathrm{ABI}$ values. For example, a large study of 13,211 healthy participants aged 21-89 years in Japan found a lower ABI in women than in men at all ages. ${ }^{55}$ In the Rotterdam study, mean ABI in women was 1.03 compared with 1.08 in men, ${ }^{56}$ whereas women had ABI values approximately 0.02 lower than men in a fully adjusted model of 1,775 healthy individuals in MESA (Multiethnic Study of Atherosclerosis). ${ }^{57}$ These observations led to the hypothesis that even in healthy women, the ABI may be lower than in men, and as a consequence lower $\mathrm{ABI}$ cutoff values would be needed in women. This sex-related difference would be associated with smaller arteries in women or to the relationship between the $\mathrm{ABI}$ and height. ${ }^{58,59}$ In the ARIC (Atherosclerosis Risk in Communities) study, although sex differences were found in the average ABI, such differences were reduced after adjusting for height, and the difference of PAD prevalence between men and women disappeared ${ }^{60}$ Even though this sex difference may pose a challenge for PAD diagnosis in women, given that the standard error for the $\mathrm{ABI}$ is $0.1-0.15$, most studies utilize an $\mathrm{ABI}$ of less than 0.9 for PAD diagnosis, and current guidelines recommend this cutoff value regardless of sex. ${ }^{3}$

Finally, some pitfalls regarding ABI use as a diagnostic tool must be taken into account. Some patients have an $\mathrm{ABI}>1.4$ as a consequence of stiff arteries. A substantial proportion of these individuals actually do have occlusive artery disease, ${ }^{61}$ requiring alternative tests to unmask PAD. This finding is more common among certain populations, such as patients with diabetes and end-stage renal disease and in the very elderly. ${ }^{50}$ Given that diabetes is a risk factor more frequently present among women with PAD (see the "Cardiovascular risk reduction" section), and that, as stated in the "Epidemiology" section, women account for most of the very elderly population, this issue poses a special challenge for PAD diagnosis in women.

\section{Duplex ultrasound}

This technique enables radiation-free noninvasive detection and localization of stenoses in the peripheral arteries. It is also highly useful for follow-up after angioplasty or to monitor bypass grafts. ${ }^{50}$ Although there are no documented sex-based differences in diagnostic sensitivity or accuracy, ${ }^{2}$ some of its limitations may pose a challenge for its generalized application, especially in women. First, in highly calcified arteries, a condition more frequently encountered among patients with diabetes and the elderly, it may be difficult to assess the lumen. ${ }^{2,50}$ Given that women account for most of the elderly with $\mathrm{PAD}^{50}$ and that diabetes is a risk factor more frequently found in women with PAD than in men, ${ }^{4}$ this methodological limitation might be more frequently seen in the former. Second, insonation in the area of open ulcers or excessive scarring may not be possible. ${ }^{50}$ This may preclude the use of duplex ultrasound in such situations, which are more common among women, who tend to be diagnosed later than men, and are therefore prone to more advanced disease. Third, in some cases of obesity, the accuracy of the test might be diminished in proximal aortoiliac arterial segments. ${ }^{2,50}$ Obese women usually have a peripheral fat distribution, particularly in the lower body. ${ }^{47}$ Therefore, this limitation of the method may pose a particular sex-related challenge.

\section{Magnetic resonance angiography, computed tomography, and contrast angiography}

These three methods provide information regarding level and extent of the disease, and help to determine whether the patient is a candidate for revascularization, contrast angiography being the gold standard for these purposes., ${ }^{2,50}$

Although women's native arterial diameters are smaller than those of men of the same age, ${ }^{63}$ there are no documented sex differences in the diagnostic sensitivity or accuracy of these advanced imaging techniques. However, some disadvantages of each specific method could pose a challenge for its use, especially in women. Magnetic resonance angiography is costly and time-consuming, ${ }^{2}$ and has the drawback of exposing patients to anxiety, especially those who are claustrophobic. ${ }^{64}$ Nephrogenic systemic fibrosis secondary to gadolinium administration in those subjects with a glomerular filtration rate $<30 \mathrm{~mL} /$ minute $/ 1.73 \mathrm{~m}^{2}{ }^{65}$ albeit rare, may occur. 
Whereas female sex does not appear to be a risk factor for nephrogenic systemic fibrosis, ${ }^{66}$ it has been documented that women require sedation to tolerate an MRI procedure more frequently than men: Murphy and Brunberg found that among patients who required sedation, women almost doubled men in a study including 939 patients undergoing MRI. ${ }^{67}$ In a study enrolling women at elevated risk of breast cancer to perform breast MRI screening, 42.1\% declined participation. Of them, 25.4\% refused owing to claustrophobia. ${ }^{68}$ Based on this information, women might probably require an alternative method, such as open MRI or CT, more frequently than men facing a revascularization procedure.

Both CT and contrast angiography require the administration of iodinated contrast agent, which limits its use in individuals with renal dysfunction. ${ }^{2}$ Iodinated contrast allergy is another potential limitation for the use of this technique. Again, women were found to be more prone to iodinated contrast media adverse drug reactions compared with men. In a prospective study of 74,717 subjects conducted to determine the incidence and characteristics of acute adverse drug reactions during the utilization of an iodinated contrast agent, the overall rate of such reactions was $2 \%$, with a higher incidence among women. ${ }^{69}$ In addition, Mortelé et al also found a significantly higher incidence of adverse events among women in a study aimed at evaluating the safety of the nonionic iodinated contrast agent iopromide in patients undergoing $\mathrm{CT}^{70}$

\section{Challenges associated with the management of PAD in women}

The management of PAD includes risk-factor reduction and, in symptomatic patients, exercise-training therapy, pharmacologic intervention and, when indicated, revascularization. ${ }^{1,50}$
Although these recommendations do not differ based on sex, women with PAD are less likely than men to receive the recommended therapy, and tend to be underrepresented in clinical trials, ${ }^{62}$ as will be discussed in the following sections.

\section{Cardiovascular risk reduction}

The major risk factors for PAD are cigarette smoking, diabetes mellitus, dyslipidemia, and hypertension. ${ }^{2,4}$ Therefore, smoking cessation and appropriate treatment of medical comorbidities with eventual antiplatelet therapy are the initial steps in PAD management. However, PAD patients without CAD are less likely to receive treatment with statins, angiotensinconverting enzyme inhibitors (ACE-Is), or antiplatelet agents compared with patients with PAD and concomitant CAD. ${ }^{71,72}$ Although guidelines do not provide differential recommendations for cardiovascular risk reduction based on sex, ${ }^{2,50}$ women with PAD are far less likely than men to receive the recommended therapy, as shown in the REACH (Reduction of Atherothrombosis for Continued Health) registry, where among 8,322 patients with PAD, women were found to be significantly less treated than men with optimal risk-factor control. ${ }^{73}$ Furthermore, it has been noticed that women may be relatively more susceptible to the burden of multiple risk factors than men. ${ }^{74}$ These sex-related differences may pose a challenge associated with cardiovascular risk reduction (Figure 1), ie, special efforts might be needed according to sex, as will be discussed in the following sections.

\section{Tobacco use}

The amount and duration of tobacco use are directly associated with the progression of PAD. ${ }^{75}$ Both ankle-pressure improvement and increased exercise tolerance have been documented after smoking cessation. ${ }^{76}$ Observational studies

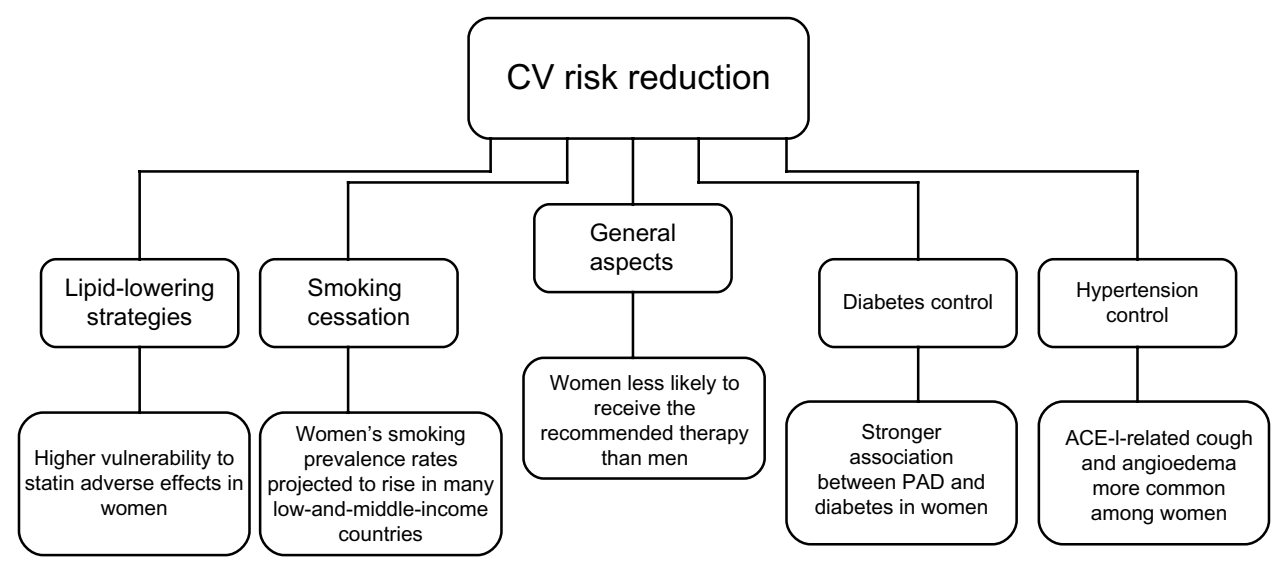

Figure I Management challenges associated with peripheral arterial disease in women: cardiovascular risk reduction. Abbreviations: ACE-I, angiotensin-converting enzyme inhibitor; CV, cardiovascular; PAD, peripheral arterial disease. 
have found that the risk of death, myocardial infarction, graft failure, and amputation are greater in those subjects who continue smoking compared with those who stop. ${ }^{77,78}$

Different studies have reported on the impact of smoking habits on PAD in men and women at high cardiovascular risk. Ness et al found that smoking has a more deleterious impact in women than in men for symptomatic PAD in older subjects, with relative risks of 4.6 and 2.5 , respectively, ${ }^{79}$ whereas Conthe Gutiérrez et al reported a different cardiovascular risk profile in high-risk women, with lighter smoking habits than men. ${ }^{80}$ Wisman et al found that men with PAD were more often smokers than women (63.6 versus $53.3 \%$, $P=0.03) .{ }^{81}$ Sigvant et al reported that in women, smoking duration already seemed to be a risk factor for PAD after 10 years of smoking, compared with 30 years for men. ${ }^{82}$ Also, passive smoking was found to be a predictor of PAD. In a study comprising 1,209 Chinese women who had never smoked, the adjusted odds ratios for PAD, defined by intermittent claudication, by $\mathrm{ABI}<0.90$, and by either intermittent claudication or $\mathrm{ABI}<0.90$, were 1.87 (95\% CI 1.30-2.68), 1.47 (95\% CI 1.07-2.03), and 1.67 (95\% CI 1.23-2.16), respectively. ${ }^{83}$

After the rapid worldwide spread of tobacco smoking before the 1950s among men, the prevalence among women started to rise as well, and although in the 1970s smoking prevalence began to decrease regardless of sex, this decline has since been detected to be weaker in females. ${ }^{84}$ As a matter of fact, while women's smoking-prevalence rates are currently lower than men's, they are projected to rise in many low- and- middle-income countries. According to the Global Youth Tobacco Survey, worldwide smoking rates among boys and girls resemble each other more than smoking rates among adult women and men. ${ }^{85}$ These issues constitute a major sex-related health burden and present a special challenge associated with the management of this risk factor among females. For instance, sex-related motivations for starting tobacco use should be taken into account when designing smoking-cessation campaigns.

\section{Diabetes}

The risk of developing PAD is proportional to the severity and duration of diabetes. ${ }^{86}$ However, studies evaluating glycemic control in diabetic subjects with PAD failed to find an association between aggressive diabetes treatment and a decrease in adverse cardiovascular events. ${ }^{87,88}$

While diabetes increases the overall risk of PAD two- to fourfold, ${ }^{2}$ it has been noted that it may increase the risk in women more than in men: in the Rotterdam study, diabetes was more prevalent among women (16\%) than men (11.9\%) with an abnormal ABI, ${ }^{89}$ and in the Framingham Heart study diabetes increased the risk of intermittent claudication 3.5 and 8.6-fold in men and women, respectively. ${ }^{90}$

Particular characteristics of PAD in diabetic subjects may pose a special challenge regarding the diagnosis and management of the disease among women, given the stronger association between PAD and diabetes in this group. To name a few examples of pitfalls that may be frequently encountered in female patients with PAD, the presentation of leg symptoms in diabetic patients may be altered by the presence of peripheral neuropathy, which may render a usually delayed diagnosis in women difficult, and pressure in the distal vessels may be falsely elevated due to the medial artery calcinosis often present in diabetic individuals.

\section{Dyslipidemia}

The risk of developing PAD increases 5\%-10\% for each 10 $\mathrm{mg} / \mathrm{dL}$ rise in total cholesterol, ${ }^{2}$ the levels of which have been found to be higher in subjects with intermittent claudication than in those without PAD in several epidemiological studies. ${ }^{91,92}$ As a matter of fact, the Framingham risk score and the Adult Treatment Panel III classify PAD as a "CAD equivalent", and recommend for such patients the same lipidlevel target as for those with CAD. ${ }^{93}$

Several studies have shown that cholesterol-lowering therapy may not only improve symptoms of intermittent claudication $^{94,95}$ but also increase walking distance to the onset of claudication. ${ }^{96}$ Statins are currently indicated for all patients with PAD to achieve a target low-density lipoprotein (LDL) cholesterol level of less than $100 \mathrm{mg} / \mathrm{dL}$, and in subjects at very high risk of ischemic events, less than $70 \mathrm{mg} / \mathrm{dL} .^{2}$ Although this recommendation does not vary according to sex, women with PAD have been found to be less likely to receive statins: in the American Vascular Association Screening Program, 87\% men versus 63\% women reported statin use, ${ }^{71}$ whereas in a Swedish study by Sigvant et al, the odds ratio for men receiving lipid-lowering therapy was 1.3 (95\% CI 1.1-1.5) when compared with women diagnosed with PAD.$^{82}$ Moreover, among 320 patients with PAD and high LDL cholesterol levels, McDermott et al reported that, during a 1-year follow-up, male PAD patients were more likely to intensify LDL cholesterol-lowering medication than female PAD patients, with an odds ratio of 3.33 (95\% CI 1.64-6.77), after adjusting for age, race, comorbidities, PAD severity, and other covariates. ${ }^{97}$

Some other issues concerning statin use among women must be considered. As discussed in the Introduction and the Prevalence 
sections, elderly women are one of the fastest-expanding population groups, accounting for a high proportion of the population burden of PAD. ${ }^{62}$ This group also exhibits the highest vulnerability to statin adverse effects, such as statin-related muscle disorders. ${ }^{98}$ Several explanations have been proposed for this observed phenomenon. Although men tend to weigh more than women, drug doses in elderly adults are rarely titrated based on weight. This may expose frail, elderly women to higher doses than their bodies are able to metabolize and eliminate efficiently. Women also tend to have a higher percentage of body fat, which can significantly increase the half-life of the more lipophilic statins. Polypharmacy among elderly women and sex-based differences in pain perception, which favor a tendency for increased reporting of pain among females, are other possible explanations for this sex-related statin vulnerability. ${ }^{98}$

The need for intensifying statin therapy in an undertreated population group, along with increased vulnerability to adverse drug reactions, constitute other challenges for PAD management among women.

\section{Hypertension}

Hypertension is a major risk factor for PAD. In fact, PAD is not only related to established hypertension but has also been found to be associated with masked hypertension, ie, normal office BP readings but elevated out-of-office BP readings. ${ }^{99,100}$

Although the association between hypertension and PAD is weaker than the association with cerebrovascular and coronary artery disease, ${ }^{2}$ it has been suggested that hypertension might play a more important role as a risk factor for PAD in women than in men. In the Framingham Heart Study, hypertension increased the risk of intermittent claudication 2.5- to fourfold in men and women, respectively, ${ }^{90}$ whereas Wisman et al reported that females with PAD had hypertension more often than males (48.5 versus $33.2 \%, P<0.01) .{ }^{81}$ This is of capital importance, given that in hypertensive adults the relative risk for total mortality and for cardiovascular morbidity and mortality is higher in subjects with an ABI equal or less than 0.9 compared with those with an ABI greater than 0.9 , as reported by Newman et al. ${ }^{53}$ Powell et al found that particularly uncontrolled systolic BP plays a strong prognostic role in the development of peripheral atherosclerosis in women. ${ }^{101}$

With regard to hypertension treatment, it is recommended that patients with PAD receive antihypertensive therapy to achieve a goal of less than 140/90 mmHg. The choice of the antihypertensive agent is less important than actual BP control in patients with PAD. ${ }^{102}$ Although concern has been raised about the fact that the use of beta-blockers may worsen the symptoms of claudication, two meta-analyses of studies published describing PAD patients with mild-to-moderate limb ischemia did not confirm the intake of beta-blockers to be associated with exacerbation of PAD symptoms. ${ }^{103}$ Interestingly, it has been noticed that the use of ACE-Is may be protective beyond that expected from BP lowering. In the HOPE (Heart Outcomes Prevention Evaluation) study, which involved 4,051 individuals with PAD, ramipril significantly reduced the rates of death, myocardial infarction, and stroke by approximately $25 \% .{ }^{104}$ Moreover, Ahimastos et al found that ramipril significantly improved pain-free walking time in subjects with symptomatic PAD. ${ }^{105}$ Therefore, it is recommended that ACE-Is should be first-line therapy in hypertensive patients with PAD. ${ }^{4}$

Antihypertensive treatment recommendations for men and women do not differ. However, women have consistently been found to be less treated than men. ${ }^{71,82}$ On the other hand, the use of ACE-Is in women has some limitations that must be taken into account, and may constitute a sex-related challenge associated with PAD management. First, ACE-Is are not recommended in sexually active women of childbearing potential due to fetal toxicity concerns. ${ }^{103}$ Second, female sex is associated with the multidrug-intolerance syndrome, of which ACE-Is are not an exception. ${ }^{106}$ In that sense, both cough and angioedema, two adverse reactions typically associated with ACE-Is, have been found to be more common among women compared with men. ${ }^{107,108}$ Third, a study conducted by Ganz et al found that ACE-I exposure was associated with breast cancer recurrence (hazard ratio $1.56,95 \%$ CI $1.02-2.39 ; P=0.04),{ }^{109}$ a finding that was not confirmed by another study ${ }^{110}$ and requires further research.

\section{Antiplatelet therapy}

The Antithrombotic Trialists' Collaboration, a meta-analysis that involved 135,000 patients randomized to placebo or antiplatelet therapy, found a $23 \%$ reduction in serious vascular events in the subset of patients with PAD allocated to the active arm. ${ }^{111}$ Antiplatelet therapy is currently indicated to reduce the risk of myocardial infarction, stroke, and vascular death in individuals with symptomatic PAD. This indication may be extrapolated to asymptomatic individuals with an ABI less than or equal to 0.9 to reduce such risks. This could be achieved either with aspirin 75-325 mg once daily or with clopidogrel $75 \mathrm{mg}$ once daily as a safe and effective alternative. ${ }^{3}$

Again, although the recommendation does not vary according to sex, women are less likely to be treated 
than men: the odds ratio for antiplatelet therapy was 1.6 (95\% CI 1.3-2.1) in a study comparing men with women conducted by Sigvant et al. ${ }^{82}$

As described for other drugs used for cardiovascular risk reduction in PAD patients, antiplatelet therapy also seems to carry sex-related characteristics that must be acknowledged by the treating physician, both in young and elderly women. While women of childbearing age are especially prone to develop aspirin sensitivity, ${ }^{112}$ in a study conducted in 3,154 elderly subjects to identify the relationship between nonsteroidal anti-inflammatory drug use (including regulardose aspirin) and gastrointestinal disturbances, female sex was an independent risk factor (odds ratio 1.32, 95\% CI 1.16-1.44) for gastrointestinal symptoms, such as abdominal pain, reflux symptoms, and indigestion syndrome. ${ }^{113}$ On the other hand, aspirin-induced asthma has been found to be more common in women than in men, with the onset of symptoms occurring significantly earlier and the disease being more progressive and severe, as reported by Szczeklik et al in a multicenter European study of 500 subjects. ${ }^{114}$

\section{Treatment for symptomatic PAD}

Regarding symptomatic PAD, different therapeutic strategies are available: exercise therapy, pharmacotherapy, and lowerextremity revascularization. ${ }^{2,50}$ From a sex-based perspective, recommendations do not differ. However, as stated in other sections of this review, some sex-related issues may interfere with the response to the treatment, accounting for another challenge associated with PAD management (Figure 2). On the other hand, women have been largely underrepresented in trials evaluating different PAD therapies, and few studies report sex-specific outcomes. ${ }^{62}$ Therefore, when making treatment decisions, it is important to have in mind that such decisions will be mostly based on the results obtained from male subjects with PAD.

\section{Supervised exercise training}

In subjects with PAD, regular walking in a supervised exercise program is effective in improving symptoms and increasing walking speed, distance, and duration. ${ }^{2,50}$ A metaanalysis of 1,200 individuals with stable leg pain found that maximal walking time was significantly improved by exercise, with a 50\%-200\% overall improvement in walking ability. ${ }^{115}$

Most studies compare one or more methods of supervised exercise training with a control group, pharmacological therapy, or a revascularization procedure. ${ }^{62}$ Of note, female participants average less than $30 \%$ of the total in the majority of randomized trials, and moreover no sex-specific analyses or outcomes are usually reported. Only one study, aimed at evaluating the efficacy of reconstructive surgery, reconstructive surgery with subsequent physical training, and physical training alone, reported results of sex-specific analyses. In this prospective, randomized trial conducted by Lundgren et al, sex did not significantly influence walking performance after treatment. ${ }^{116}$ Of course, more research is needed in order to establish whether women respond differently than men to supervised exercise training.

\section{Pharmacological therapy}

Patients with symptomatic PAD may also benefit from pharmacologic treatment. Among the available drugs, cilostazol, a

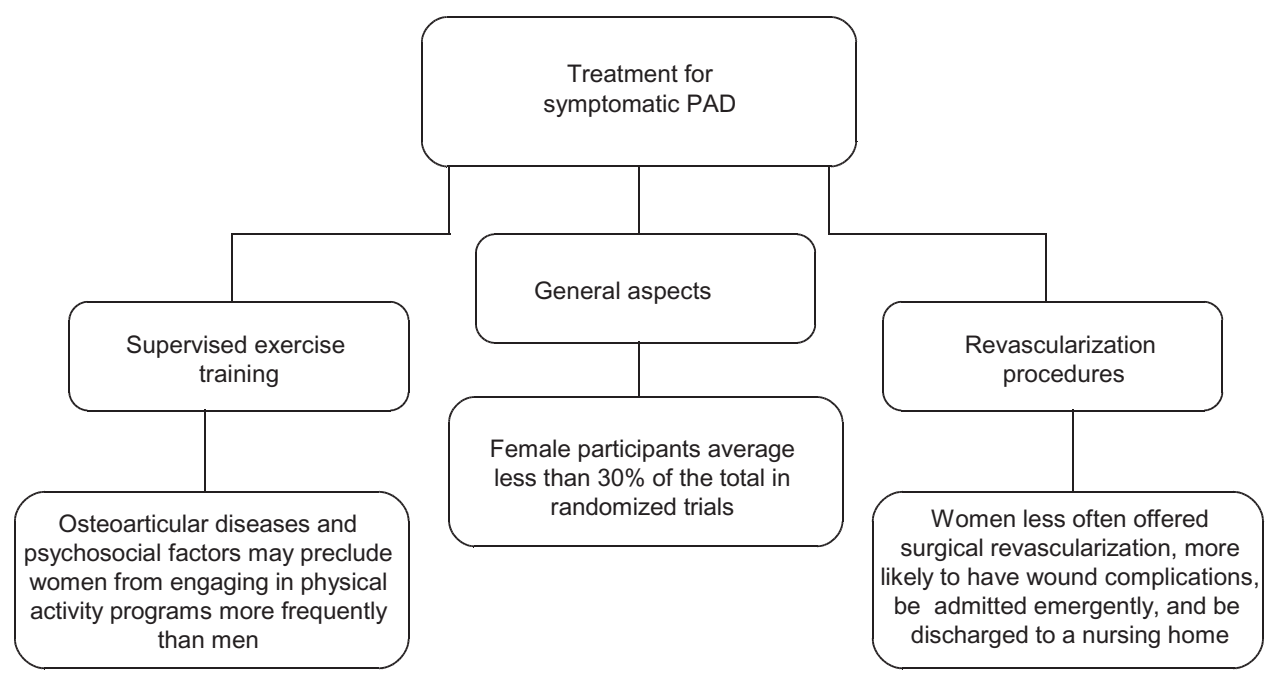

Figure 2 Treatment for symptomatic peripheral arterial disease: sex-related challenges. Abbreviation: PAD, peripheral arterial disease. 
phosphodiesterase inhibitor that inhibits platelet aggregation and has arterial vasodilator properties, has the most conclusive evidence to support its use as first-line pharmacologic therapy for intermittent claudication. ${ }^{2,4}$ Several randomized clinical trials have been conducted, concluding that cilostazol at a dose of $100 \mathrm{mg}$ twice daily improves both pain-free and maximal treadmill walking distance compared with placebo. ${ }^{117,118}$ Cilostazol has also been shown to cause small increases in ABI values, to raise serum high-density lipid cholesterol concentration, ${ }^{118}$ and to improve quality of life. ${ }^{119}$

Again, women have been largely underrepresented within the trials evaluating pharmacologic therapy, accounting for less than $30 \%$ of the population recruited in most of these studies. $^{62}$ However, sex-specific analyses demonstrated no statistical difference in estimated treatment effects between men and women. ${ }^{120}$

\section{Revascularization}

Symptomatic patients that would benefit from revascularization, either endovascular treatment or surgery, should be evaluated on the grounds of vascular anatomy suitability, severity of symptoms, failure of medical therapies and lack of significant comorbidities. ${ }^{2}$ Women have been largely underrepresented in PAD revascularization trials, where they account for $32 \%$ of trial participants, ${ }^{62}$ which results in treatment decision making being mostly supported by results obtained in men.

Although treatment options are similar for both sexes, women are less often offered surgical revascularization and are more likely to be admitted emergently and discharged to a nursing home. ${ }^{48,121}$ Smaller vessel size, more advanced disease, later age at the onset of the disease, psychosocial factors, and worse surgical outcomes have all been proposed as possible explanations for this observation. ${ }^{62,122}$ Of note, amputation-free survival has been reported in many studies to be similar in women and men, ${ }^{64}$ which may constitute a strong argument in favor of revascularization in women, despite the aforementioned sex-related differences.

Regarding other outcomes associated with revascularization, it has been noted that women tend to have an inferior patency after surgical lower-extremity revascularization than men. ${ }^{62}$ Nguyen et al observed that both race and sex were predictors of patency after lower-extremity saphenous vein bypass, with black women having the highest risk of graft loss at 1 year, ${ }^{123}$ whereas Ballard et al described a relative risk of 4.6 for bypass or stent thrombosis in women compared with men. ${ }^{124}$ However, these results have not been confirmed by another studies, which did not identify sex differences related to patency. ${ }^{125}$
While conflicting results have been reported regarding sex effects on survival after PAD revascularization, ${ }^{62,126}$ studies have consistently shown that female sex is a risk factor for wound complications after revascularization procedures. ${ }^{127,128}$ Matsi and Manninen noted a significantly higher incidence of bleeding complications ( $15 \%$ versus $6 \%$ ) in women undergoing percutaneous lower-extremity angioplasty compared with men, ${ }^{129}$ and Belkin et al observed a greater frequency of infections, hematomas, and seromas in women undergoing lowerextremity arterial bypass (13.5\% versus $3.3 \%) .{ }^{130}$ Finally, in a study involving 1,400 subjects who underwent lower-extremity revascularization for critical limb ischemia, female sex was an independent predictor of wound complications, with an odds ratio of $1.4(95 \%$ CI $1.08-1.8) .{ }^{131}$

\section{Conclusion}

PAD is a common disease among women, and is expected to increase in the coming years. Several issues regarding sex-related differences in clinical presentation, comorbidities, interpretation of diagnostic methods, and medical and surgical management pose important challenges associated with PAD in women that should be addressed and overcome.

Although the evidence related to prognostic implications of PAD in women is compelling, this group has classically been underrepresented in research studies. Therefore, more investigation taking into account sex differences will probably improve our understanding and contribute to better management of the disease.

\section{Acknowledgment}

We are grateful to Ms Erika Barochiner for language editing.

\section{Disclosure}

The authors report no conflicts of interest in this work.

\section{References}

1. Rooke TW, Hirsch AT, Misra S, et al. Management of patients with peripheral artery disease (compilation of 2005 and 2011 ACCF/AHA Guideline Recommendations): a report of the American College of Cardiology Foundation/American Heart Association Task Force on Practice Guidelines. J Am Coll Cardiol. 2013;61(14):1555-1570.

2. Hirsch AT, Haskal ZJ, Hertzer NR, et al. ACC/AHA 2005 Practice Guidelines for the management of patients with peripheral arterial disease (lower extremity, renal, mesenteric, and abdominal aortic): a collaborative report from the American Association for Vascular Surgery/Society for Vascular Sur. Circulation. 2006;113(11):e463-e654.

3. Rooke TW, Hirsch AT, Misra S, et al. 2011 ACCF/AHA focused update of the guideline for the management of patients with peripheral artery disease (updating the 2005 guideline): a report of the American College of Cardiology Foundation/American Heart Association Task Force on Practice Guidelin. Catheterization Cardiovasc Interv. 2012;79(4):501-531. 
4. Chi Y-W, Jaff MR. Optimal risk factor modification and medical management of the patient with peripheral arterial disease. Catheterization and cardiovascular interventions: official journal of the Society for Cardiac Angiography and Interventions. 2008;71(4):475-489.

5. Teodorescu VJ, Vavra AK, Kibbe MR. Peripheral arterial disease in women. Journal of vascular surgery. 2013;57(4 Supp1):18S-26S.

6. Higgins JP, Higgins JA. Epidemiology of peripheral arterial disease in women. Journal of epidemiology/Japan Epidemiological Association. 2003;13(1):1-14.

7. Criqui MH, Fronek A, Barrett-Connor E, Klauber MR, Gabriel S, Goodman D. The prevalence of peripheral arterial disease in a defined population. Circulation. 1985;71(3):510-515.

8. Vavra AK, Kibbe MR. Women and peripheral arterial disease. Women's Health (London, England). 2009;5(6):669-683.

9. Criqui MH, Denenberg JO, Langer RD, Fronek A. The epidemiology of peripheral arterial disease: importance of identifying the population at risk. Vascular medicine (London, England). 1997;2(3):221-226.

10. Ness J, Aronow WS. Prevalence of coexistence of coronary artery disease, ischemic stroke, and peripheral arterial disease in older persons, mean age 80 years, in an academic hospital-based geriatrics practice. Journal of the American Geriatrics Society. 1999;47(10):1255-1256.

11. Hirsch AT, Criqui MH, Treat-Jacobson D, et al. Peripheral arterial disease detection, awareness, and treatment in primary care. JAMA: the journal of the American Medical Association. 2001;286(11):1317-1324.

12. Smolderen KG, Pelle AJ. Letter by Smolderen and Pelle regarding article, "Efficacy and safety of varenicline for smoking cessation in patients with cardiovascular disease: a randomized trial". Circulation. 2010;122(9):e445; author reply e446.

13. Heidrich H, Hermann GM. Concomitant neurological and orthopaedic diseases in the presence of peripheral arterial disease: a prospective study. VASA. Zeitschrift für Gefässkrankheiten. 2006;35(2):101-105.

14. Yeil H, Hepgüler S, Oztürk C, Capacı K, Yeil M. Prevalence of symptomatic knee, hand and hip osteoarthritis among individuals 40 years or older: a study conducted in İzmir city. Acta orthopaedica et traumatologica turcica. 2013;47(4):231-235.

15. Zhang J, Song L, Liu G, et al. Risk factors for and prevalence of knee osteoarthritis in the rural areas of Shanxi Province, North China: a COPCORD study. Rheumatology international. 2013.

16. Aronow WS. Osteoporosis, osteopenia, and atherosclerotic vascular disease. Archives of medical science: AMS. 2011;7(1):21-26.

17. Von Mühlen D, Allison M, Jassal SK, Barrett-Connor E. Peripheral arterial disease and osteoporosis in older adults: the Rancho Bernardo Study. Osteoporosis international: a journal established as result of cooperation between the European Foundation for Osteoporosis and the National Osteoporosis Foundation of the USA. 2009;20(12):2071-2078.

18. Mangiafico RA, Russo E, Riccobene S, et al. Increased prevalence of peripheral arterial disease in osteoporotic postmenopausal women. Journal of bone and mineral metabolism. 2006;24(2):125-131.

19. Ness J, Aronow WS. Comparison of prevalence of atherosclerotic vascular disease in postmenopausal women with osteoporosis or osteopenia versus without osteoporosis or osteopenia. The American journal of cardiology. 2006;97(10):1427-1428.

20. Gessl A, Lemmens-Gruber R, Kautzky-Willer A. Thyroid disorders. Handbook of experimental pharmacology. 2012;(214):361-386.

21. Powell J, Zadeh JA, Carter G, Greenhalgh RM, Fowler PB. Raised serum thyrotrophin in women with peripheral arterial disease. The British journal of surgery. 1987;74(12):1139-1141.

22. Mya MM, Aronow WS. Increased prevalence of peripheral arterial disease in older men and women with subclinical hypothyroidism. The journals of gerontology. Series A, Biological sciences and medical sciences. 2003;58(1):68-69.

23. Mazzeffi MA, Lin H-M, Flynn BC, O'Connell TL, DeLaet DE. Hypothyroidism and the risk of lower extremity arterial disease. Vascular health and risk management. 2010;6:957-962.

24. Brito MB, Nobre F, Vieira CS. Hormonal contraception and cardiovascular system. Arquivos brasileiros de cardiologia. 2011;96(4): e81-e89.
25. Van Den Bosch MAAJ, Kemmeren JM, Tanis BC, et al. The RATIO study: oral contraceptives and the risk of peripheral arterial disease in young women. Journal of thrombosis and haemostasis: JTH. 2003;1(3):439-444.

26. Ben-Ami S, Oron G, Ben-Haroush A, Blickstein D, Hod M, Bar J. Primary atherothrombotic occlusive vascular events in premenopausal women with history of adverse pregnancy outcome. Thrombosis research. 2010;125(2):124-127.

27. Weissgerber TL, Turner ST, Bailey KR, et al. Hypertension in pregnancy is a risk factor for peripheral arterial disease decades after pregnancy. Atherosclerosis. 2013;229(1):212-216.

28. Westendorp IC, in't Veld BA, Grobbee DE, et al. Hormone replacement therapy and peripheral arterial disease: the Rotterdam study. Archives of internal medicine. 2000;160(16):2498-2502.

29. Hulley S, Grady D, Bush T, et al. Randomized trial of estrogen plus progestin for secondary prevention of coronary heart disease in postmenopausal women. Heart and Estrogen/progestin Replacement Study (HERS) Research Group. JAMA: the journal of the American Medical Association. 1998;280(7):605-613.

30. Rossouw JE, Anderson GL, Prentice RL, et al. Risks and benefits of estrogen plus progestin in healthy postmenopausal women: principal results From the Women's Health Initiative randomized controlled trial. JAMA: the journal of the American Medical Association. 2002;288(3):321-333.

31. Timaran $\mathrm{CH}$, Stevens SL, Freeman MB, Goldman MH. Infrainguinal arterial reconstructions in patients with aortoiliac occlusive disease: the influence of iliac stenting. Journal of vascular surgery. 2001;34(6):971-978.

32. Mazhari R, Hsia J. Prevalence, clinical significance, and management of peripheral arterial disease in women: is there a role for postmenopausal hormone therapy? Vascular health and risk management. 2005;1(2):111-117.

33. Newman AB, Shemanski L, Manolio TA, et al. Ankle-arm index as a predictor of cardiovascular disease and mortality in the Cardiovascular Health Study. The Cardiovascular Health Study Group. Arteriosclerosis, thrombosis, and vascular biology. 1999;19(3):538-545.

34. Diehm C, Allenberg JR, Pittrow D, et al. Mortality and vascular morbidity in older adults with asymptomatic versus symptomatic peripheral artery disease. Circulation. 2009;120(21):2053-2061.

35. Vogt MT, Cauley JA, Newman AB, Kuller LH, Hulley SB. Decreased ankle/arm blood pressure index and mortality in elderly women. JAMA: the journal of the American Medical Association. 1993;270(4):465-469.

36. Fowkes FGR, Murray GD, Butcher I, et al. Ankle brachial index combined with Framingham Risk Score to predict cardiovascular events and mortality: a meta-analysis. JAMA: the journal of the American Medical Association. 2008;300(2):197-208.

37. Newman AB, Tyrrell KS, Kuller LH. Mortality over four years in SHEP participants with a low ankle-arm index. Journal of the American Geriatrics Society. 1997;45(12):1472-1478.

38. Hirsch AT, Murphy TP, Lovell MB, et al. Gaps in public knowledge of peripheral arterial disease: the first national PAD public awareness survey. Circulation. 2007;116(18):2086-2094.

39. Lovell M, Harris K, Forbes T, et al. Peripheral arterial disease: lack of awareness in Canada. The Canadian journal of cardiology. 2009;25(1):39-45

40. Bush RL, Kallen MA, Liles DR, Bates JT, Petersen LA. Knowledge and awareness of peripheral vascular disease are poor among women at risk for cardiovascular disease. The Journal of surgical research. 2008;145(2):313-319.

41. Vegda K, Nie JX, Wang L, Tracy CS, Moineddin R, Upshur REG. Trends in health services utilization, medication use, and health conditions among older adults: a 2-year retrospective chart review in a primary care practice. BMC health services research. 2009;9:217.

42. Vogt MT, Cauley JA, Kuller LH, Hulley SB. Prevalence and correlates of lower extremity arterial disease in elderly women. American journal of epidemiology. 1993;137(5):559-568. 
43. Sigvant B, Wiberg-Hedman K, Bergqvist D, et al. A population-based study of peripheral arterial disease prevalence with special focus on critical limb ischemia and sex differences. Journal of vascular surgery. 2007;45(6):1185-1191.

44. HooiJD, KesterAD, Stoffers HE, OverdijkMM, van ReeJW,KnottnerusJA. Incidence of and risk factors for asymptomatic peripheral arterial occlusive disease: a longitudinal study. American journal of epidemiology. 2001;153(7):666-672.

45. McDermott MM, Guralnik JM, Ferrucci L, et al. Asymptomatic peripheral arterial disease is associated with more adverse lower extremity characteristics than intermittent claudication. Circulation. 2008;117(19):2484-2491

46. McDermott MM, Greenland P, Liu K, et al. Sex differences in peripheral arterial disease: leg symptoms and physical functioning. Journal of the American Geriatrics Society. 2003;51(2):222-228.

47. Geer EB, Shen W. Gender differences in insulin resistance, body composition, and energy balance. Gender medicine. 2009;6 Suppl 1:60-75.

48. Feinglass J, McDermott MM, Foroohar M, Pearce WH. Gender differences in interventional management of peripheral vascular disease: evidence from a blood flow laboratory population. Annals of vascular surgery. 1994;8(4):343-349.

49. Brevetti G, Bucur R, Balbarini A, et al. Women and peripheral arterial disease: same disease, different issues. Journal of cardiovascular medicine (Hagerstown, Md.). 2008;9(4):382-388.

50. Tendera M, Aboyans V, Bartelink M-L, et al. ESC Guidelines on the diagnosis and treatment of peripheral artery diseases: Document covering atherosclerotic disease of extracranial carotid and vertebral, mesenteric, renal, upper and lower extremity arteries: the Task Force on the Diagnosis and Treatm. European heart journal. 2011;32(22):2851-2906.

51. Dormandy JA, Rutherford RB. Management of peripheral arterial disease (PAD). TASC Working Group. TransAtlantic Inter-Society Consensus (TASC). Journal of vascular surgery. 2000;31(1 Pt 2):S1-S296.

52. Fowkes FG. The measurement of atherosclerotic peripheral arterial disease in epidemiological surveys. International journal of epidemiology. 1988;17(2):248-254.

53. Newman AB, Sutton-Tyrrell K, Vogt MT, Kuller LH. Morbidity and mortality in hypertensive adults with a low ankle/arm blood pressure index. JAMA: the journal of the American Medical Association. 1993;270(4):487-489.

54. McKenna M, Wolfson S, Kuller L. The ratio of ankle and arm arterial pressure as an independent predictor of mortality. Atherosclerosis. 1991;87(2-3):119-128.

55. Ishida A, Miyagi M, Kinjo K, Ohya Y. Age- and sex-related effects on ankle-brachial index in a screened cohort of Japanese: the Okinawa Peripheral Arterial Disease Study (OPADS). European journal of preventive cardiology. 2012

56. Meijer WT, Hoes AW, Rutgers D, Bots ML, Hofman A, Grobbee DE. Peripheral arterial disease in the elderly: The Rotterdam Study. Arteriosclerosis, thrombosis, and vascular biology. 1998;18(2):185-192.

57. Aboyans V, Criqui MH, McClelland RL, et al. Intrinsic contribution of gender and ethnicity to normal ankle-brachial index values: the MultiEthnic Study of Atherosclerosis (MESA). Journal of vascular surgery. 2007;45(2):319-327.

58. Bild DE, Bluemke DA, Burke GL, et al. Multi-ethnic study of atherosclerosis: objectives and design. American journal of epidemiology. 2002;156(9):871-881.

59. Hiatt WR, Hoag S, Hamman RF. Effect of diagnostic criteria on the prevalence of peripheral arterial disease. The San Luis Valley Diabetes Study. Circulation. 1995;91(5):1472-1479.

60. Zheng Z-J, Rosamond WD, Chambless LE, et al. Lower extremity arterial disease assessed by ankle-brachial index in a middle-aged population of African Americans and whites: the Atherosclerosis Risk in Communities (ARIC) Study. American journal of preventive medicine. 2005;29(5 Suppl 1):42-49.

61. Aboyans V, Ho E, Denenberg JO, Ho LA, Natarajan L, Criqui MH. The association between elevated ankle systolic pressures and peripheral occlusive arterial disease in diabetic and nondiabetic subjects. Journal of vascular surgery. 2008;48(5):1197-1203.
62. Hirsch AT, Allison MA, Gomes AS, et al. A call to action: women and peripheral artery disease: a scientific statement from the American Heart Association. Circulation. 2012;125(11):1449-1472.

63. AhChong AK, Chiu KM, Wong M, Yip AW. The influence of gender difference on the outcomes of infrainguinal bypass for critical limb ischaemia in Chinese patients. European journal of vascular and endovascular surgery: the official journal of the European Society for Vascular Surgery. 2002;23(2):134-139.

64. Versluis MJ, Teeuwisse WM, Kan HE, van Buchem MA, Webb AG, van Osch MJ. Subject tolerance of 7 T MRI examinations. Journal of magnetic resonance imaging: JMRI. 2013;38(3):722-725.

65. Telgmann L, Sperling M, Karst U. Determination of gadolinium-based MRI contrast agents in biological and environmental samples: a review. Analytica chimica acta. 2013;764:1-16.

66. Sadowski EA, Bennett LK, Chan MR, et al. Nephrogenic systemic fibrosis: risk factors and incidence estimation. Radiology. 2007;243(1):148-157.

67. Murphy KJ, Brunberg JA. Adult claustrophobia, anxiety and sedation in MRI. Magnetic resonance imaging. 1997;15(1):51-54

68. Berg WA, Blume JD, Adams AM, et al. Reasons women at elevated risk of breast cancer refuse breast MR imaging screening: ACRIN 6666. Radiology. 2010;254(1):79-87.

69. Kopp AF, Mortele KJ, Cho YD, Palkowitsch P, Bettmann MA, Claussen CD. Prevalence of acute reactions to iopromide: postmarketing surveillance study of 74,717 patients. Acta radiologica (Stockholm, Sweden: 1987). 2008;49(8):902-911.

70. Mortelé KJ, Oliva M-R, Ondategui S, Ros PR, Silverman SG. Universal use of nonionic iodinated contrast medium for CT: evaluation of safety in a large urban teaching hospital. AJR. American journal of roentgenology. 2005;184(1):31-34.

71. Cheanvechai V, Harthun NL, Graham LM, Freischlag JA, Gahtan V. Incidence of peripheral vascular disease in women: is it different from that in men? The Journal of thoracic and cardiovascular surgery. 2004;127(2):314-317.

72. Zeymer U, Parhofer KG, Pittrow D, et al. Risk factor profile, management and prognosis of patients with peripheral arterial disease with or without coronary artery disease: results of the prospective German REACH registry cohort. Clinical research in cardiology: official journal of the German Cardiac Society. 2009;98(4):249-256.

73. Cacoub PP, Abola MTB, Baumgartner I, et al. Cardiovascular risk factor control and outcomes in peripheral artery disease patients in the Reduction of Atherothrombosis for Continued Health (REACH) Registry. Atherosclerosis. 2009;204(2):e86-e92.

74. Paul TK, Chen W, Srinivasan SR, Toprak A, He J, Berenson GS. Gender divergence on the impact of multiple cardiovascular risk factors on the femoral artery intima-media thickness in asymptomatic young adults: the Bogalusa Heart Study. The American journal of the medical sciences. 2012;343(1):40-45.

75. Freund KM, Belanger AJ, D'Agostino RB, Kannel WB. The health risks of smoking. The Framingham Study: 34 years of follow-up. Annals of epidemiology. 1993;3(4):417-424.

76. Quick CR, Cotton LT. The measured effect of stopping smoking on intermittent claudication. The British journal of surgery. 1982;69 Suppl:S24-S26.

77. Jonason T, Bergström R. Cessation of smoking in patients with intermittent claudication. Effects on the risk of peripheral vascular complications, myocardial infarction and mortality. Acta medica Scandinavica. 1987;221(3):253-260.

78. Willigendael EM, Teijink JAW, Bartelink M-L, Peters RJG, Büller HR, Prins MH. Smoking and the patency of lower extremity bypass grafts: a meta-analysis. Journal of vascular surgery. 2005;42(1):67-74.

79. Ness J, Aronow WS, Ahn C. Risk factors for symptomatic peripheral arterial disease in older persons in an academic hospital-based geriatrics practice. Journal of the American Geriatrics Society. 2000;48(3):312-314.

80. Conthe Gutiérrez P, Lobos Bejarano JM, González Juanatey JR, Gil Núñez A, Pajuelo Fernández FJ, Novials Sardá A. [Different approach in high-cardiovascular-risk women, compared to men: a multidisciplinary study-Spain]. Medicina clínica. 2003;120(12):451-455. 
81. Wisman PP, Tangelder MJ, van Hattum ES, de Borst GJ, Moll FL. Young women with PAD are at high risk of cardiovascular complications. European journal of vascular and endovascular surgery: the official journal of the European Society for Vascular Surgery. 2012;43(4):441-445.

82. Sigvant B, Wiberg-Hedman K, Bergqvist D, Rolandsson O, Wahlberg E. Risk factor profiles and use of cardiovascular drug prevention in women and men with peripheral arterial disease. European journal of cardiovascular prevention and rehabilitation: official journal of the European Society of Cardiology, Working Groups on Epidemiology and Prevention and Cardiac Rehabilitation and Exercise Physiology. 2009;16(1):39-46.

83. He Y, Lam TH, Jiang B, et al. Passive smoking and risk of peripheral arterial disease and ischemic stroke in Chinese women who never smoked. Circulation. 2008;118(15):1535-1540.

84. Osler M, Prescott E, Godtfredsen N, Hein HO, Schnohr P. Gender and determinants of smoking cessation: a longitudinal study. Preventive medicine. 1999;29(1):57-62.

85. Warren CW, Jones NR, Eriksen MP, Asma S. Patterns of global tobacco use in young people and implications for future chronic disease burden in adults. Lancet. 2006;367(9512):749-753.

86. Beks PJ, Mackaay AJ, de Neeling JN, de Vries H, Bouter LM, Heine RJ. Peripheral arterial disease in relation to glycaemic level in an elderly Caucasian population: the Hoorn study. Diabetologia. 1995;38(1):86-96.

87. Intensive blood-glucose control with sulphonylureas or insulin compared with conventional treatment and risk of complications in patients with type 2 diabetes (UKPDS 33). UK Prospective Diabetes Study (UKPDS) Group. Lancet. 1998;352(9131):837-853.

88. Effect of intensive diabetes management on macrovascular events and risk factors in the Diabetes Control and Complications Trial. The American journal of cardiology. 1995;75(14):894-903.

89. Meijer WT, Grobbee DE, Hunink MG, Hofman A, Hoes AW. Determinants of peripheral arterial disease in the elderly: the Rotterdam study. Archives of internal medicine. 2000;160(19):2934-2938.

90. Kannel WB, McGee DL. Update on some epidemiologic features of intermittent claudication: the Framingham Study. Journal of the American Geriatrics Society. 1985;33(1):13-18.

91. Murabito JM, Evans JC, Nieto K, Larson MG, Levy D, Wilson PW f. Prevalence and clinical correlates of peripheral arterial disease in the Framingham Offspring Study. American heart journal. 2002;143(6):961-965.

92. Bainton D, Sweetnam P, Baker I, Elwood P. Peripheral vascular disease: consequence for survival and association with risk factors in the Speedwell prospective heart disease study. British heart journal. 1994;72(2):128-132.

93. Executive Summary of The Third Report of The National Cholesterol Education Program (NCEP) Expert Panel on Detection, Evaluation, And Treatment of High Blood Cholesterol In Adults (Adult Treatment Panel III). JAMA: the journal of the American Medical Association. 2001;285(19):2486-2497.

94. Buchwald H, Bourdages HR, Campos CT, Nguyen P, Williams SE, Boen JR. Impact of cholesterol reduction on peripheral arterial disease in the Program on the Surgical Control of the Hyperlipidemias (POSCH). Surgery. 1996;120(4):672-679.

95. Pedersen TR, Kjekshus J, Pyörälä K, et al. Effect of simvastatin on ischemic signs and symptoms in the Scandinavian simvastatin survival study (4S). The American journal of cardiology. 1998;81(3):333-335.

96. Mohler ER, Hiatt WR, Creager MA. Cholesterol reduction with atorvastatin improves walking distance in patients with peripheral arterial disease. Circulation. 2003;108(12):1481-1486.

97. McDermott MM, Greenland P, Reed G, et al. Gender differences in cholesterol-lowering medication prescribing in peripheral artery disease. Vascular medicine (London, England). 2011;16(6):428-435.

98. Bhardwaj S, Selvarajah S, Schneider EB. Muscular effects of statins in the elderly female: a review. Clinical interventions in aging 2013;8:47-59.

99. Delsart P, Marboeuf P, Delhaye C, Lemesle G, Mounier-Vehier C. Should we screen for masked hypertension in patient with vascular disease? Vascular health and risk management. 2010;6:333-338.
100. Barochiner J, Cuffaro PE, Aparicio LS, et al. Predictors of masked hypertension among treated hypertensive patients: an interesting association with orthostatic hypertension. American journal of hypertension. 2013;26(7):872-878.

101. Powell TM, Glynn RJ, Buring JE, Creager MA, Ridker PM, Pradhan AD. The relative importance of systolic versus diastolic blood pressure control and incident symptomatic peripheral artery disease in women. Vascular medicine (London, England). 2011;16(4):239-246.

102. De Buyzere ML, Clement DL. Management of hypertension in peripheral arterial disease. Progress in cardiovascular diseases. 50(4):238-263.

103. Mancia G, Fagard R, Narkiewicz K, et al. 2013 ESH/ESC Guidelines for the management of arterial hypertension: the Task Force for the management of arterial hypertension of the European Society of Hypertension (ESH) and of the European Society of Cardiology (ESC). Journal of hypertension. 2013;31(7):1281-1357.

104. Yusuf S, Sleight P, Pogue J, Bosch J, Davies R, Dagenais G. Effects of an angiotensin-converting-enzyme inhibitor, ramipril, on cardiovascular events in high-risk patients. The Heart Outcomes Prevention Evaluation Study Investigators. The New England journal of medicine. 2000;342(3):145-153.

105. Ahimastos AA, Lawler A, Reid CM, Blombery PA, Kingwell BA. Brief communication: ramipril markedly improves walking ability in patients with peripheral arterial disease: a randomized trial. Annals of internal medicine. 2006;144(9):660-664.

106. Macy E, Ho NJ. Multiple drug intolerance syndrome: prevalence, clinical characteristics, and management. Annals of allergy, asthma and immunology: official publication of the American College of Allergy, Asthma, and Immunology. 2012;108(2):88-93.

107. Seeland U, Regitz-Zagrosek V. Sex and gender differences in cardiovascular drug therapy. Handbook of experimental pharmacology. 2012;(214):211-236.

108. Malde B, Regalado J, Greenberger PA. Investigation of angioedema associated with the use of angiotensin-converting enzyme inhibitors and angiotensin receptor blockers. Annals of allergy, asthma and immunology: official publication of the American College of Allergy, Asthma, and Immunology. 2007;98(1):57-63.

109. Ganz PA, Habel LA, Weltzien EK, Caan BJ, Cole SW. Examining the influence of beta blockers and ACE inhibitors on the risk for breast cancer recurrence: results from the LACE cohort. Breast cancer research and treatment. 2011;129(2):549-556.

110. Chae YK, Valsecchi ME, Kim J, et al. Reduced risk of breast cancer recurrence in patients using ACE inhibitors, ARBs, and/or statins. Cancer investigation. 2011;29(9):585-593.

111. Collaborative meta-analysis of randomised trials of antiplatelet therapy for prevention of death, myocardial infarction, and stroke in high risk patients. BMJ (Clinical research ed.). 2002;324(7329):71-86.

112. Speer F, Denison TR, Baptist JE. Aspirin allergy. Annals of allergy. 1981;46(3):123-126.

113. Pilotto A, Franceschi M, Leandro G, Di Mario F. NSAID and aspirin use by the elderly in general practice: effect on gastrointestinal symptoms and therapies. Drugs and aging. 2003;20(9):701-710.

114. SzczeklikA, Nizankowska E, Duplaga M. Natural history of aspirin-induced asthma. AIANE Investigators. European Network on Aspirin-Induced Asthma. The European respiratory journal. 2000;16(3):432-436.

115. Watson L, Ellis B, Leng GC. Exercise for intermittent claudication. The Cochrane database of systematic reviews. 2008;(4):CD000990.

116. Lundgren F, Dahllöf AG, Lundholm K, Scherstén T, Volkmann R. Intermittent claudication--surgical reconstruction or physical training? A prospective randomized trial of treatment efficiency. Annals of surgery. 1989;209(3):346-355.

117. Beebe HG, Dawson DL, Cutler BS, et al. A new pharmacological treatment for intermittent claudication: results of a randomized, multicenter trial. Archives of internal medicine. 1999;159(17):2041-2050.

118. Money SR, Herd JA, Isaacsohn JL, et al. Effect of cilostazol on walking distances in patients with intermittent claudication caused by peripheral vascular disease. Journal of vascular surgery. 1998;27(2):267-274; discussion 274-275. 
119. Regensteiner JG, Ware JE, McCarthy WJ, et al. Effect of cilostazol on treadmill walking, community-based walking ability, and healthrelated quality of life in patients with intermittent claudication due to peripheral arterial disease: meta-analysis of six randomized controlled trials. Journal of the American Geriatrics Society. 2002;50(12):1939-1946.

120. Pande RL, Hiatt WR, Zhang P, Hittel N, Creager MA. A pooled analysis of the durability and predictors of treatment response of cilostazol in patients with intermittent claudication. Vascular medicine (London, England). 2010;15(3):181-188.

121. Egorova N, Vouyouka AG, Quin J, et al. Analysis of gender-related differences in lower extremity peripheral arterial disease. Journal of vascular surgery. 2010;51(2):372-378.e1; discussion 378-379.

122. Hernandez-Vila EA. Peripheral arterial disease in women: the effect of gender on diagnosis and treatment. Texas Heart Institute journal / from the Texas Heart Institute of St. Luke's Episcopal Hospital, Texas Children's Hospital. 2011;38(2):154-156.

123. Nguyen LL, Hevelone N, Rogers SO, et al. Disparity in outcomes of surgical revascularization for limb salvage: race and gender are synergistic determinants of vein graft failure and limb loss. Circulation. 2009;119(1):123-130.

124. Ballard JL, Bergan JJ, Singh P, Yonemoto H, Killeen JD. Aortoiliac stent deployment versus surgical reconstruction: analysis of outcome and cost. Journal of vascular surgery. 1998;28(1):94-101; discussion 101-103.

125. Ballotta E, Gruppo M, Lorenzetti R, Piatto G, DaGiau G, Toniato A. The impact of gender on outcome after infrainguinal arterial reconstructions for peripheral occlusive disease. Journal of vascular surgery. 2012;56(2):343-352.
126. Lo RC, Bensley RP, Dahlberg SE, et al. Presentation, treatment, and outcome differences between men and women undergoing revascularization or amputation for lower extremity peripheral arterial disease. Journal of vascular surgery. 2013.

127. Jain AK, Velazquez-Ramirez G, Goodney PP, Edwards MS, Corriere MA. Gender-based analysis of perioperative outcomes associated with lower extremity bypass. The American surgeon. 2011;77(7):844-849.

128. Greenblatt DY, Rajamanickam V, Mell MW. Predictors of surgical site infection after open lower extremity revascularization. Journal of vascular surgery. 2011;54(2):433-439.

129. Matsi PJ, Manninen HI. Complications of lower-limb percutaneous transluminal angioplasty: a prospective analysis of 410 procedures on 295 consecutive patients. Cardiovascular and interventional radiology. 21(5):361-366.

130. Belkin M, Conte MS, Donaldson MC, Mannick JA, Whittemore AD. The impact of gender on the results of arterial bypass with in situ greater saphenous vein. American journal of surgery. 1995;170(2):97-102.

131. Nguyen LL, Brahmanandam S, Bandyk DF, et al. Female gender and oral anticoagulants are associated with wound complications in lower extremity vein bypass: an analysis of 1404 operations for critical limb ischemia. Journal of vascular surgery. 2007;46(6):1191-1197.
Vascular Health and Risk Management

\section{Publish your work in this journal}

Vascular Health and Risk Management is an international, peerreviewed journal of therapeutics and risk management, focusing on concise rapid reporting of clinical studies on the processes involved in the maintenance of vascular health; the monitoring, prevention and treatment of vascular disease and its sequelae; and the involvement of

\section{Dovepress}

metabolic disorders, particularly diabetes. This journal is indexed on PubMed Central and MedLine. The manuscript management system is completely online and includes a very quick and fair peer-review system, which is all easy to use. Visit http://www.dovepress.com/ testimonials.php to read real quotes from published authors. 